\title{
Determination of the creep exponent of a power-law creep solid using indentation tests
}

\section{Yanping Cao}

Published online: 18 October 2007

(C) Springer Science+Business Media B.V. 2007

\section{Erratum to: Mech Time-Depend Mater \\ DOI: 10.1007/s11043-007-9033-6}

The numbered heading labels of the tables were changed during typesetting. The corresponding citation at one place in the text has not been changed accordingly. Namely, the 'Table 1' in the first paragraph of section 3, above the section 3.1, should be 'Table 2' because 'Table 2' gives the material properties.

The online version of the original article can be found under doi:10.1007/s11043-007-9033-6.

\section{Y. Cao $(\bowtie)$}

Forschungszentrum Karlsruhe, Institut für Materialforschung II, Hermann-von-Helmholtz-Platz 1, 76344 Eggenstein-Leopoldshafen, Germany

e-mail: cypqj1@yahoo.com

Y. Cao

Max-Planck-Institut für Eisenforschung, Max-Planck-Straße 1, 40237 Düsseldorf, Germany 